05

\title{
Флуктуационный объем аморфных веществ в модели делокализованных атомов
}

\author{
(C) Д.С. Сандитов ${ }^{1,2}$, А.А. Машанов ${ }^{1}$ \\ ${ }^{1}$ Бурятский государственный университет, \\ 670000 Улан-Удэ, Россия \\ ${ }^{2}$ Институт фризического материаловедения СО РАН, \\ 670047 Улан-Удэ, Россия \\ e-mail: Sanditov@bsu.ru
}

(Поступило в Редакцию 27 октбря 2016 г. В окончательной редакции 3 мая 2017 г.)

Развито представление о соответствии „образования дырки“ в аморфных веществах процессу делокализации атома. Показано, что при стандартной скорости охлаждения $3 \mathrm{~K} / \mathrm{min}$ значения доли флуктуационного объема, рассчитанные по данным о вязкости и по данным зависимости температуры стеклования от скорости охлаждения расплава, оказываются одинаковыми. Приведены результаты применения уравнения Бартенева к бескислородным стеклам.

DOI: 10.21883/JTF.2017.11.45125.2085

\section{Введение}

В последние годы применительно к стеклообразным системам развита модель делокализованных атомов [1,2]. Одним из важных параметров модели является флуктуационный объем аморфных веществ, обусловленный смещениями частиц из равновесных положений.

В настоящей работе обсуждается природа доли флуктуационного объема, замороженной при температуре стеклования, а также понятия „дырка“ и „делокализация атома“" в жидкостях и стеклах [3-7]. Рассмотрены следствия, вытекающие отсюда, для практических приложений.

\section{Теория свободного объема и модель делокализованных атомов}

Свободный объем жидкости $V_{f}$ определяется как суммарный объем дырок [3]

$$
V_{f}=\left(V-V_{0}\right)=v_{h} N_{h}
$$

где $N_{h}$ - число дырок, $v_{h}$ - объем дырки, $V_{0}$ - занятый объем. Для относительного числа дырок используется соотношение, заимствованное из теории кристаллической решетки,

$$
\frac{N_{h}}{N}=\exp \left(-\frac{\varepsilon_{h}+v_{h} p}{k T}\right) .
$$

Здесь $\varepsilon_{h}$ - энергия образования дырки, $N$ - число атомов. Если дырка в кристалле представляет собой пустой узел решетки, то в случае жидкости она остается не совсем ясным понятием, как отмечал сам Я.И. Френкель. Свободному объему жидкости он придавал смысл избыточного объема в сравнении с объемом твердого тела $\left(, V_{0}\right.$ - истинный объем тела в отсутствие дырок“ [3]).
Нами развито представление о том, что „образованию дырки в жидкости“ (по Френкелю) соответствует процесс делокализации атома - его флуктуационное смещение из равновесного положения.

Методами статистической физики без привлечения понятий „дырка“ и „свободный объем“ выводится формула для относительного числа делокализованных атомов $[1,2]$

$$
\frac{N_{e}}{N}=\exp \left(-\frac{\Delta \varepsilon_{e}+p \Delta v_{e}}{k T}\right) .
$$

Здесь $\Delta \varepsilon_{e}=p_{i} \Delta v_{e}-$ энергия делокализации атома, равная работе смещения атома из равновесного положения, совершаемой против внутреннего давления $p_{i}$, обусловленного силами межатомного притяжения, $\Delta v_{e}-$ элементарный флуктуационный объем, необходимый для смещения атома (объем делокализации атома).

Данный подход назван моделью делокализованных атомов $[1,8]$, одним из важных параметров которой является флуктуационный объем аморфного вещества $\Delta V_{e}$ :

$$
\Delta V_{e}=N_{e} \Delta v_{e}
$$

Как видно, зависимости (1) и (2) совпадают. Из их сравнения следует, что избыточный свободный объем $V_{f}=N_{h} v_{h}$ приобретает смысл флуктуационного объема (3), а число дырок $N_{h}$ - числа делокализованных атомов $N_{e}$. Энергия образования дырки $\varepsilon_{h}$ совпадает с энергией делокализации атома $\Delta \varepsilon_{e}$ и объем дырки $v_{h}-$ с объемом делокализации атома $\Delta v_{e}$.

Теорию свободного объема по Френкелю уже давно стали называть теорией флуктуационного свободного объема $[6,9]$, подчеркивая тем самым флуктуационный характер процесса образования дырки (см. (1)). Из изложенного выше видно, что математический аппарат модели делокализованных атомов совпадает с формализмом теории флуктуационного свободного объема. 
С точки зрения модели делокализованных атомов термин „флуктуационный свободный объем“ целесообразно переименовать во „флуктуационный объем“ без прилагательного „свободный“, ибо он по существу не является свободным объемом, а термин „свободный объем“ предлагаем сохранить для традиционного ван-дерваальсова свободного объема. Классический свободный объем по Ван-дер-Ваальсу $V_{F}$ - пустое пространство между атомами - входит в состав атомных комплексов структуры. Его называют структурно-обусловленным [5], геометрическим [6] свободным объемом.

\section{Флуктуационный объем в области стеклования. Оценка по данным о вязкости}

В области стеклования жидкости температурная зависимость времени структурной релаксации $\tau(T)$ и вязкости $\eta(T)$ успешно описывается уравнением ВЛФ (Вильямса-Ландела-Ферри) [9,10], получившим широкое распространение в физике аморфных полимеров [9] и стекол [6]:

$$
\ln a_{T}=C_{1} \frac{T-T_{g}}{T-T_{g}+C_{2}}, \quad a_{T}=\frac{\tau(T)}{\tau\left(T_{g}\right)}=\frac{\eta(T)}{\eta\left(T_{g}\right)} .
$$

Эмпирические постоянные данного уравнения $C_{1}$ и $C_{2}$ выражаются через параметры модели делокализованных атомов следующим образом [1]:

$$
C_{1}=\frac{1}{f_{g}} \text { и } C_{2}=\frac{f_{g}}{\beta_{f}},
$$

где $f_{g}=\left(\Delta V_{e} / V\right)_{T=T_{g}}$ - доля флуктуационного объема, замороженная при температуре стеклования $T_{g}, \beta_{f}-$ коэффициент теплового расширения флуктуационного объема при $T=T_{g} \quad\left(\beta_{f}=(d f / d T)_{T=T_{g}}\right)$. Эти формулы (5) были получены ранее в терминах теории флуктуационного свободного объема [6,9].

Для проверки применимости уравнения ВЛФ к температурной зависимости вязкости $\eta(T)$ в области стеклования, а также для расчета $C_{1}$ и $C_{2}$ можно представить его в виде уравнения прямой

$$
-\frac{\left(T-T_{g}\right)}{\ln a_{T}}=\frac{1}{C_{1}}\left(T-T_{g}\right)+\frac{C_{2}}{C_{1}}
$$

и построить график в координатах $\left[-\left(T-T_{g}\right) / k \ln a_{T}\right]-$ $-\left(T-T_{g}\right)$. Указанная зависимость в этих координатах оказывается линейной в достаточно широком интервале температур (рис. 1) (у силикатных стекол от $T_{g}$ до $\left.T_{g}+700 \mathrm{~K}\right)$, что подтверждает справедливость уравнения ВЛФ. Из этих графиков определяются значения $C_{1}$ и $C_{2}[6]$.

В соответствии с одной из формул (5) доля флуктуационного объема $f_{g}$, замороженная при температуре стеклования, рассчитывается по данным о параметре

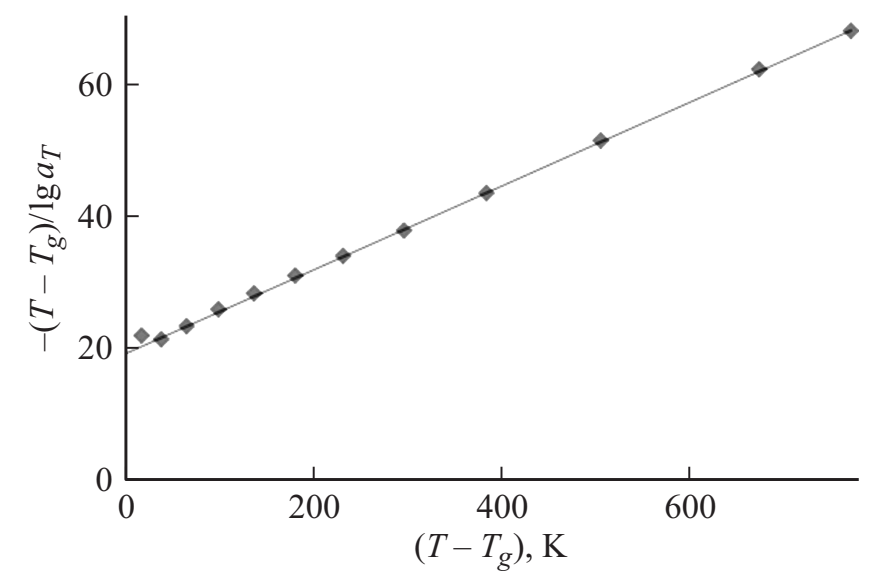

Рис. 1. Температурная зависимость вязкости оконного силикатного стекла в координатах уравнения ВЛФ: $-\left(T-T_{g}\right) / \lg a_{T}-\left(T-T_{g}\right) . a_{T}=\eta(T) / \eta\left(T_{g}\right)$.

Таблица 1. Доля флуктуационного объема $f_{g}$, замороженная при температуре стеклования $T_{g}$, и параметры уравнения ВЛФ $C_{1}$ и $C_{2}$ для неорганических стекол, органических аморфных полимеров и металлических аморфных сплавов

\begin{tabular}{c|c|c|c|c}
\hline Аморфные вещества & $T_{g}, \mathrm{~K}$ & $C_{1}$ & $C_{2}$ & $f_{g}$ \\
\hline \multicolumn{4}{c}{ Натриево-силикатные стекла $\mathrm{Na}_{2} \mathrm{O}-\mathrm{SiO}_{2}[17]$} \\
\hline $\mathrm{Na}_{2} \mathrm{O}$, mol.\% & & & & \\
15 & 782 & 36 & 430 & 0.028 \\
20 & 759 & 36 & 390 & 0.028 \\
25 & 739 & 35 & 355 & 0.028 \\
30 & 721 & 35 & 322 & 0.028 \\
33 & 712 & 35 & 304 & 0.028 \\
35 & 705 & 35 & 291 & 0.028 \\
\hline
\end{tabular}

Аморфные органические полимеры [9] и селен [6]

\begin{tabular}{c|c|c|c|c}
\hline Поливинилацетат & 305 & 36 & 47 & 0.028 \\
Натуральный каучук & 300 & 38 & 54 & 0.026 \\
Метакрилат этиловый & 335 & 40 & 65 & 0.025 \\
Селен & 303 & 32 & 58 & 0.031 \\
\hline
\end{tabular}

\begin{tabular}{c|c|c|c|c}
\hline \multicolumn{4}{c}{ Металлические стекла (аморфные сплавы [2]) } \\
\hline $\mathrm{Pd}_{40} \mathrm{Ni}_{40} \mathrm{P}_{20}$ & 602 & 39 & 93 & 0.026 \\
$\mathrm{Pt}_{60} \mathrm{Ni}_{15} \mathrm{P}_{25}$ & 500 & 37 & 95 & 0.027 \\
$\mathrm{Pd}_{77.5} \mathrm{Cu}_{6} \mathrm{Si}_{16.5}$ & 653 & 38 & 100 & 0.026 \\
$\mathrm{Fe}_{80} \mathrm{P}_{13} \mathrm{C}_{7}$ & 736 & 38 & 120 & 0.026
\end{tabular}

уравнения ВЛФ $C_{1}$ и слабо зависит от природы стеклообразующих веществ $[1,2]$ (табл. 1)

$$
f_{g}=\frac{1}{C_{1}} \approx \text { const } \approx 0.020-0.030 \text {. }
$$

У натриево-силикатных стекол $\mathrm{Na}_{2} \mathrm{O}-\mathrm{SiO}_{2}$ (у аморфных веществ одного класса) при изменении содержания $\mathrm{Na}_{2} \mathrm{O}$ в пределах от 15 до $35 \mathrm{~mol} . \%$ величина $f_{g}$ оказывается практически универсальной постоянной: $f_{g}=0.028$ (табл. 1). 
Таблица 2. Параметры уравнения Бартенева (7) и доля флуктуационного объема $f_{g}$ при температуре стеклования

\begin{tabular}{c|c|c|c|c|c|c|c}
\hline Стекло & $T_{g}, \mathrm{~K}$ & $a_{1} \cdot 10^{3}, \mathrm{~K}^{-1}$ & $a_{2} \cdot 10^{5}, \mathrm{~K}^{-1}$ & $a_{2} / a_{1}$ & $a_{1} / a_{2}+2.9$ & $f_{g}$ (уравнение (12)) & Литература \\
\hline Канифоль & 313 & 3.098 & 8.3 & 0.027 & 40 & 0.025 & {$[13]$} \\
ПС & 345 & 2.78 & 9.0 & 0.032 & 34 & 0.029 & {$[13]$} \\
ПММА & 349 & 2.75 & 8.9 & 0.032 & 34 & 0.029 & {$[13]$} \\
Каучук СКС-30 & 208 & 4.62 & 15.0 & 0.032 & 34 & 0.029 & {$[14]$} \\
Каучук СКС-18 & 218 & 4.41 & 13.2 & 0.030 & 36 & 0.028 & {$[14]$} \\
Каучук СКС-40 & 246 & 3.90 & 12.0 & 0.031 & 35 & 0.028 & {$[14]$} \\
Эбонит & 349 & 2.72 & 9.6 & 0.035 & 31 & 0.032 & {$[13]$} \\
Борный ангидрид & 534 & 1.81 & 5.6 & 0.031 & 35 & 0.028 & {$[13]$} \\
& & \multicolumn{7}{|c|}{ Силикатное стекло* (mas.\%) } & & \\
№ 1 & 714 & 1.34 & 4.28 & 0.032 & 34 & 0.029 & {$[13]$} \\
№ 2 & 744 & 1.29 & 4.24 & 0.033 & 33 & 0.030 & {$[13]$} \\
№ 3 & 809 & 1.19 & 3.60 & 0.030 & 36 & 0.028 & {$[13]$} \\
№ 4 & 885 & 1.086 & 3.33 & 0.031 & 35 & 0.028 & {$[13]$} \\
№ 5 & 1025 & 0.94 & 2.67 & 0.028 & 39 & 0.026 & {$[13]$}
\end{tabular}

Примечание . * Силикатные стекла: № $1: \mathrm{SiO}_{2}-55.3, \mathrm{Na}_{2} \mathrm{O}-3.8, \mathrm{~K}_{2} \mathrm{O}-9.2, \mathrm{PbO}-30, \mathrm{Al}_{2} \mathrm{O}_{3}-1.7$; № 2: $\mathrm{SiO}_{2}-38.1, \mathrm{Na}_{2} \mathrm{O}-1.3$, $\mathrm{K}_{2} \mathrm{O}-2.5, \mathrm{PbO}-52, \mathrm{Al}_{2} \mathrm{O}_{3}-3.4, \mathrm{~B}_{2} \mathrm{O}_{3}-1.8, \mathrm{CaO}-0.5, \mathrm{MgO}-0.4$; № 3: $\mathrm{SiO}_{2}-70.9, \mathrm{Na}_{2} \mathrm{O}-16.1, \mathrm{~K}_{2} \mathrm{O}-0.5, \mathrm{CaO}-8.1, \mathrm{MgO}-2.9$, другие оксиды 1,4; № 4: $\mathrm{SiO}_{2}-56, \mathrm{CaO}-7.4, \mathrm{MgO}-8, \mathrm{~K}_{2} \mathrm{O}-2, \mathrm{Al}_{2} \mathrm{O}_{3}-25$. ПС - полистирол, ПММА - полиметилметакрилат.

Предполагается, что значения $f_{g}$ в табл. 1 относятся к „стандартной“ скорости охлаждения расплава $q=0.05 \mathrm{~K} / \mathrm{s}$ (см. ниже).

\section{Оценка $f_{g}$ по данным о зависимости температуры стеклования от скорости охлаждения}

Проблема зависимости температуры стеклования от скорости охлаждения расплава является важнейшей частью теории стеклообразного состояния. Она важна и для практики, например, при разработке оптимального режима отжига и закалки стекол.

Бартенев [11] на основе предложенного им критерия стеклования и известной формулы времени релаксации, записанной при температуре стеклования, предложил следующую зависимость температуры стеклования от скорости охлаждения расплава $q=d T / d t$ :

$$
\frac{1}{T_{g}}=a_{1}-a_{2} \ln q \text {. }
$$

Оказывается, что отношение параметров уравнения Бартенева тесно связано с долей флуктуационного объема $f_{g}[12]$

$$
\frac{1}{f_{g}}=\left(\frac{a_{1}}{a_{2}}\right)-\ln q .
$$

Было установлено, что отношение эмпирических постоянных $a_{1}$ и $a_{2}$ слабо зависит от природы аморфных веществ - практически одинаково для них $\left(a_{2} / a_{1} \approx 0.03\right)$ (табл. 2) [13-15]

$$
\frac{a_{2}}{a_{1}} \approx \text { const } \approx 0.027-0.035 \text {. }
$$

Отсюда следует, что при данной скорости охлаждения $q=$ const величина $f_{g}$ в равенстве (8) также есть константа $f_{g} \approx$ const.

В связи с зависимостью $T_{g}=T_{g}(q)$ было предложено пользоваться понятием о стандартной скорости охлаждения [13-15]

$$
q=3 \mathrm{~K} / \mathrm{min}=0.05 \mathrm{~K} / \mathrm{s} \text {, }
$$

принятой в технологии стекла. В дилатометрии стекол и полимеров фактически во всех странах мира используют, как правило, такую же скорость охлаждения (10). Ввиду слабой полулогарифмической зависимости $T_{g}$ от $q$ небольшие колебания $q$ около стандартного значения особо не сказываются на величине $T_{g}$, за редкими исключениями. При изменении $q$ в 10 раз температура стеклования смещается лишь на малую величину $\Delta T=0.03 T_{g} \quad[13,15]$. Поэтому обычно полагают, что подавляющее большинство имеющихся данных о $T_{g}$ относится к стандартной скорости охлаждения.

Из выражения (8) выразим $f_{g}$

$$
f_{g}=\left(\frac{a_{1}}{a_{2}}-\ln q\right)^{-1} \text {. }
$$

Подставив в это равенство значения $a_{1}$ и $a_{2}$ из табл. 2 и $\ln q=-2.9(q=0.05 \mathrm{~K} / \mathrm{s})$, вычислим долю флуктуационного объема $f_{g}$ при стандартной скорости охлаждения (табл. 2)

$$
f_{g}=\left(\frac{a_{1}}{a_{2}}+2.9\right)^{-1} \approx \text { const } \approx 0.026-0.032 .
$$

Примечательно то обстоятельство, что эти значения находятся в согласии с результатом расчета $f_{g}$ по данным о вязкости (6) (табл. 1). 
Таблица 3. Параметры уравнения Бартенева (7) и доля флуктуационного объема $f_{g}$ для бескислородных и ряда оксидных стекол [17]

\begin{tabular}{c|c|c|c|c|c}
\hline Стекло & $T_{g}, \mathrm{~K}$ & $a_{1} \cdot 10^{3}, \mathrm{~K}^{-1}$ & $a_{2} \cdot 10^{5}, \mathrm{~K}^{-1}$ & $a_{2} / a_{1}$ & $f_{g}(12)$ \\
\hline $\mathrm{Se}-\mathrm{Bi}$ & 309 & 3.12 & 10.45 & 0.034 & 0.031 \\
$\mathrm{Se}-\mathrm{Ga}$ & 315 & 3.09 & 9.29 & 0.030 & 0.027 \\
$\mathrm{In}-\mathrm{Se}$ & 316.7 & 3.09 & 5.54 & 0.018 & 0.017 \\
$\mathrm{As}-\mathrm{Sb}-\mathrm{Se}$ & 444.8 & 2.15 & 6.74 & 0.031 & 0.028 \\
$\mathrm{GeO}_{2}$ & 762 & 1.23 & 3.45 & 0.028 & 0.026 \\
$\mathrm{P}_{2} \mathrm{O}_{5}-\mathrm{TeO}_{2}$ & 578 & 1.67 & 4.99 & 0.030 & 0.027 \\
$\mathrm{SiO}_{2}-\mathrm{Al}_{2} \mathrm{O}_{3}-\mathrm{B}_{2} \mathrm{O}_{3}-$ & & & 3.20 & 0.036 & 0.032 \\
$\mathrm{P}_{2} \mathrm{O}_{5}-\mathrm{MgO}_{-} \mathrm{Na}_{2} \mathrm{O}-\mathrm{K}_{2} \mathrm{O}$ & 1064 & 0.89 & & &
\end{tabular}

\section{Обсуждение результатов}

1. Из совпадения расчетов $f_{g}$ двумя разными способами (по соотношениям (6) и (12)) следует, что способ вычисления $f_{g}$ по данным о вязкости (6) относится так же, как и в случае (12), к стандартной скорости охлаждения (10).

В формуле $(11)$ отношение $\left(a_{1} / a_{2}\right) \approx 35-40$ не зависит от величины $q$ и заметно превышает второе слагаемое (при $q=0.05 \mathrm{~K} / \mathrm{s}$ )

$$
\frac{a_{1}}{a_{2}} \gg \ln q
$$

поэтому доля флуктуационного объема $f_{g}$ практически совпадает с отношением $a_{2} / a_{1}$ и слабо зависит от скорости охлаждения $q$. Она определяется, главным образом, „предельным“ значением вязкости $\eta_{g}$ при $T=T_{g}$, которое также слабо зависит от $q$ : $\eta_{g} \approx$ const $\approx 10^{12} \mathrm{~Pa} \cdot \mathrm{s}[12,16]$.

Таким образом, постоянство отношения параметров уравнения Бартенева $a_{2} / a_{1} \approx$ const тесно связано с постоянством доли флуктуационного объема $f_{g} \approx$ const в модели делокализованных атомов.

Температура стеклования $T_{g}$ измеряется как в режиме нагревания стекла в процессе его размягчения, так и в режиме охлаждения стеклообразующего расплава. Значения $T_{g}$, определенные этими способами, несколько отличаются. Тем не менее характеры зависимости $T_{g}$ от скорости нагревания и скорости охлаждения оказываются идентичными. Экспериментальные точки ложатся на прямую в координатах $\left(1 / T_{g}\right)-\lg q$, соответствующую уравнению (7).

В работах Бартенева с сотрудниками [13-15] проведено систематическое исследование зависимости $T_{g}=$ $=T_{g}(q)$ в широком диапазоне скоростей нагревания $0.2-50 \mathrm{~K} / \mathrm{min}$. В них изучены различные аморфные вещества: канифоль, эбонит, органические аморфные полимеры, силикатные стекла с температурами стеклования от 218 до $1025 \mathrm{~K}$ (табл. 2). Показана оправданность уравнения Бартенева (7), за редкими исключениями.

В табл. 3 приводятся результаты нашего исследования бескислородных стекол $\mathrm{Se}-\mathrm{Ga}, \mathrm{Se}-\mathrm{Bi}$, In-Se, $\mathrm{As}-\mathrm{Sb}-\mathrm{Se}$.

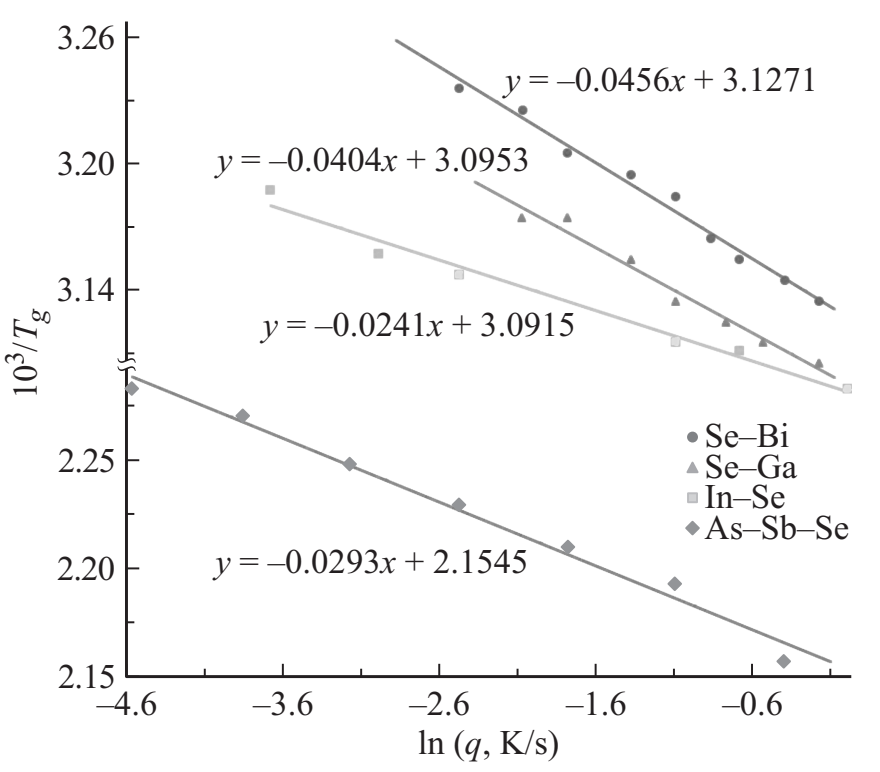

Рис. 2. Зависимость температуры стеклования от скорости нагревания для бескислородных стекол в координатах $1 / T_{g}-\ln q$. Содержание $\mathrm{Se} / \mathrm{Bi}, \mathrm{mol} \%$ : 77.28/22.72; $\mathrm{Se} / \mathrm{Ga}$, mol.\%: 95.56/4.44; In/Se, mol.\%: 7.11/92.89; As/Sb/Se, mol.\%: 32.91/7.64/59.45. Использованы данные [17]. Se-Bi [(25097) Abu El-Oyoun M., 2000], Se-Ga [(26436) El-Oyoun M.A., 2003], In-Se [(26416) Abd El-Moiz A.B, 1992], As-Sb-Se [(25427) Mahadevan S., 1986].

Использованы данные в базе SciGlass [17]. Для них наблюдаются те же закономерности, что и для оксидных стекол: $a_{2} / a_{1} \approx 0.028-0.034, f_{g} \approx 0.026-0.032$ (табл. 3). Лишь стекло In-Se выпадает из общей закономерности. Зависимость $1 / T_{g}$ от $\ln q$ оказывается линейной (рис. 2), что подтверждает применимость уравнения (7) к этим и другим системам (рис. 3).

2. При делокализации атома речь идет о локальной упругой деформации межатомных связей без разрыва последних. Под „делокализацией атома“, например, в неорганических стеклах и их расплавах подразумевается смещение мостикового атома (типа атома кислорода в мостике $\mathrm{Si}-\mathrm{O}-\mathrm{Si}$ ), связанное с локальной низкоактивационной деформацией сетки валентных связей $[1,8]$. 


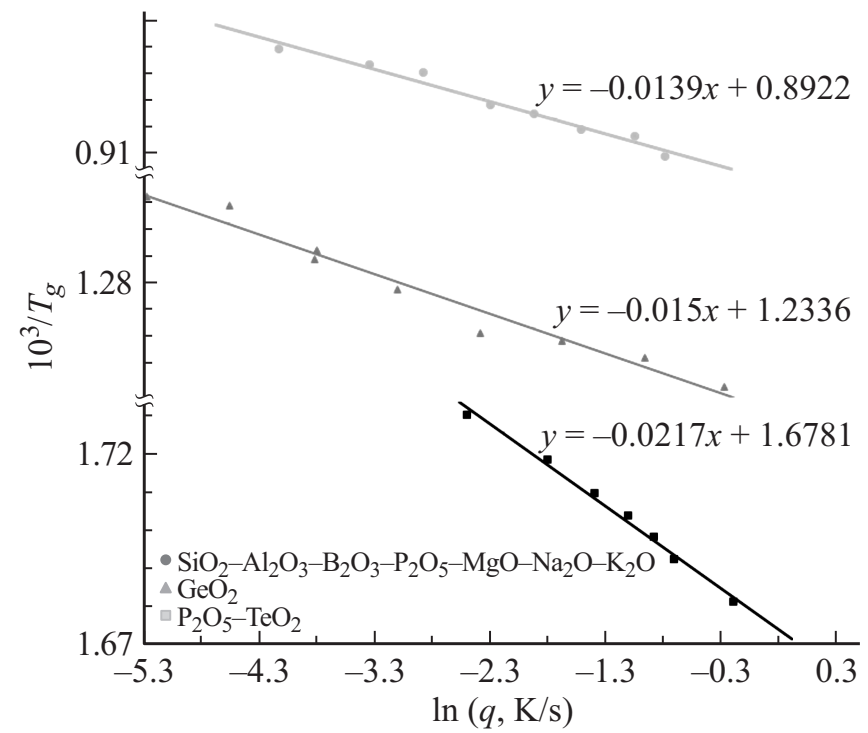

Рис. 3. Зависимость обратной величины температуры стеклования $1 / T_{g}$ от логарифма скорости охлаждения $\ln q$ для оксидных стекол. Содержание $\mathrm{SiO}_{2} / \mathrm{Al}_{2} \mathrm{O}_{3} \mathrm{~B}_{2} \mathrm{O}_{3} /$ $\mathrm{P}_{2} \mathrm{O}_{5} / \mathrm{MgO} / \mathrm{Na}_{2} \mathrm{O} / \mathrm{K}_{2} \mathrm{O}$, mol.\%: 55.09/22.01/1.01/1.72/19.78/0.32/ 0.0507; $\quad \mathrm{GeO}_{2}$, mol.\%: 100; $\mathrm{P}_{2} \mathrm{O}_{5} / \mathrm{TeO}_{2}, \quad \mathrm{~mol} . \%$ : 69.39/ 30.61. Использованы данные [17]. $\mathrm{SiO}_{2}-\mathrm{Al}_{2} \mathrm{O}_{3}-\mathrm{B}_{2} \mathrm{O}_{3}-$ $\mathrm{P}_{2} \mathrm{O}_{5}-\mathrm{MgO}-\mathrm{Na}_{2} \mathrm{O}-\mathrm{K}_{2} \mathrm{O}$ [(24241) Watanabe K., 1994], $\mathrm{GeO}_{2}$ [(14972) Bruning R., 1999], $\mathrm{P}_{2} \mathrm{O}_{5}-\mathrm{TeO}_{2}$ [(8772) Elkholy M.M., 1995].<smiles>C[Si](C)(C)O[Si](C)(C)O[Si](C)(C)O[Si](C)(C)O[Si](C)(C)O[Si](C)(C)O[Si](C)(C)O[Si](C)(C)C</smiles><smiles>C[Si](C)O[Si](C)(C)O[Si](C)(C)O[Si](C)(C)[O-]</smiles>

Рис. 4. Схема переключения валентной связи при вязком течении силикатного стекла [18]. $(A-B)$ - делокализация мостикового атома кислорода в мостике $\mathrm{Si}-\mathrm{O}-\mathrm{Si} ;(B-C)-$ переключение валентной связи.

На рис. 4 приводится схема элементарного акта вязкого течения силикатного стекла по Немилову [18], который, как мы считаем $[19,20]$, состоит из двух этапов: (1) делокализации мостикового атома кислорода $(A-B)$ и $(2)$ переключения валентной связи $(B-C)$. Полагаем, что делокализация атома - предельное смещение мостикового атома кислорода - служит необходимым условием переключения валентной связи и, следовательно, самого вязкого течения. Без делокализации атома („пускового механизма“ текучести) невозможно вязкое течение. Поэтому замораживание процесса делокализации активного атома в области стеклования приводит к прекращению вязкого течения и к переходу расплава в стеклообразное состояние.

3. Остановимся на некоторых следствиях, имеющих отношение к практическим приложениям.
3.1. Представление о том, что образование дырки в жидкостях и стеклах обусловлено делокализацией атома, позволяет устранить ряд противоречий между свободно-объемной теорией и экспериментальными данными.

С точки зрения теории свободного объема, вязкость жидкости, измеренная при ее постоянном объеме $V=$ const, не должна меняться с изменением температуры, поскольку свободный объем остается без изменения. Однако, согласно опытным данным, вязкость уменьшается при нагревании при постоянном объеме. Такое же явление наблюдается и для других молекулярнокинетических процессов $[21,22]$.

Данное кажущееся противоречие возникает из-за ошибочной трактовки свободного объема как структурнообусловленного ван-дер-ваальсова свободного объема, который не меняется при изменении температуры при $V=$ const. В соответствии с предлагаемым механизмом образования дырки вполне возможно изменение флуктуационного свободного объема с изменением температуры при $V=$ const, так как локальные тепловые смещения (делокализации) атомов могут происходить в принципе и при неизменном объеме системы. Нагревание жидкости при $V=$ const сопровождается ростом числа делокализованных атомов („дырок“), что приводит к снижению вязкости.

Другой аналогичный пример кажущегося противоречия встречается в работе [23], где утверждается, что исследование массивных и ленточных металлических стекол (состава $\mathrm{Pd}_{40} \mathrm{Cu}_{30} \mathrm{Ni}_{10} \mathrm{P}_{20}$ ), отличающихся на четыре порядка по скорости закалки и имеющих поэтому примерно вдвое различающийся свободный объем, не выявило сколько-нибудь заметной разницы их сдвиговых вязкостей, что противоречит теории свободного объема. Здесь авторы [23] под свободным объемом подразумевают структурно-обусловленный свободный объем, который практически не оказывает влияния на вязкость.

Очевидно, что процесс делокализации атома в локальных областях как массивных, так и ленточных металлических стекол (с разными геометрическими свободными объемами) происходит одинаково, поэтому доли флуктуационного свободного объема и значения сдвиговых вязкостей должны быть близки в обоих случаях, что и подтверждает эксперимент [23].

3.2. Величина $f_{g}$ входит в основные формулы модели делокализованных атомов, с помощью которых можно объяснить, а иногда предсказать некоторые явления в стеклах [1],

$$
\begin{aligned}
\Delta \varepsilon_{e} & =R T_{g} \ln \left(1 / f_{g}\right), \\
\Delta v_{e} & =\frac{3(1-2 \mu) R T_{g}}{f_{g} E},
\end{aligned}
$$

где $R$ - газовая постоянная, $\mu$ - коэффициент Пуассона, $E$ - модуль упругости при одноосной деформации.

В качестве примера рассмотрим так называемый эффект пластичности стекол [6,24-29]. Под действием механического напряжения, превышающего некоторый 
предел $\sigma_{y}$, при $20^{\circ} \mathrm{C}$ в силикатных стеклах возникает деформация, которая после снятия внешнего напряжения может сохраняться сколь угодно долго. Однако примечательно то обстоятельство, что при нагревании (ниже $T_{g}$ ) данная деформация релаксирует практически до исчезновения. Следовательно, она оказывается замороженной обратимой вязкоупругой деформацией. Тем не менее, следуя многим авторам, будем пользоваться термином „пластическая“, а величину $\sigma_{y}$ назовем пределом текучести („Пластичности“).

Аналогичная замороженная деформация наблюдается у аморфных органических полимеров [24]. У массивных металлических стекол недавно обнаружены также замороженная вязкоупругая деформация и ее термостимулированная релаксация [25], основные закономерности которых фактически такие же, как у неорганических стекол и аморфных полимеров.

„Пластичность“ хрупких неорганических стекол удобно изучать методом микротвердости. При вдавливании алмазной пирамидки Виккерса (и других заостренных инденторов) в силикатное стекло образуется „пластичный“ микроотпечаток (при $20^{\circ} \mathrm{C}$ ). При этом микротвердость по Виккерсу $H_{v}$ у силикатных, германатных и других неорганических стекол совпадает с предельным напряжением $\sigma_{y}$. Следовательно, микротвердость для них служит пределом текучести $H_{v} \approx \sigma_{y}$ [26].

Представление о том, что элементарный акт „пластической“ деформации стекол сводится к делокализации атома (кинетической единицы), находится в удовлетворительном согласии с экспериментальными данными: расчеты предела текучести и энергии активации этой деформации согласуются с экспериментом [27].

Предел текучести $\sigma_{y}$ имеет смысл напряжения, необходимого для критического смещения (делокализации) кинетической единицы. По величине он совпадает с

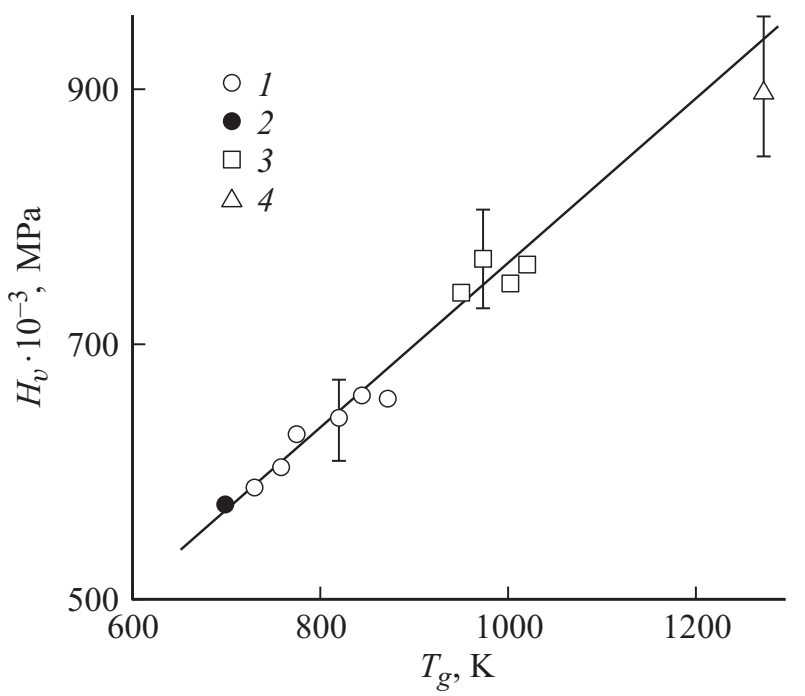

Рис. 5. Корреляция между микротвердостью $H_{v}$ и температурой стеклования $T_{g}$ силикатных стекол. $1-$ свинцовосиликатное, 2 - щелочносиликатное, 3 - алюмосиликатное, 4 кварцевое.
Таблица 4. Параметры модели делокализованных атомов для щелочно-силикатных стекол $\mathrm{R}_{2} \mathrm{O}-\mathrm{SiO}_{2}(\mathrm{R}=\mathrm{Na}, \mathrm{K})$

\begin{tabular}{c|c|c|c|c}
\hline Стекло $\mathrm{R}_{2} \mathrm{O}-\mathrm{SiO}_{2}$ & $T_{g}, \mathrm{~K}$ & $f_{g}$ & $\Delta v_{e}, \AA^{3}$ & $\Delta \varepsilon_{e}, \mathrm{~kJ} / \mathrm{mol}$ \\
\hline $\mathrm{Na}_{2} \mathrm{O}, \mathrm{mol} \%$ & & & & \\
19.6 & 744 & 0.029 & 10 & 19 \\
30.1 & 713 & 0.028 & 9 & 18 \\
36.3 & 694 & 0.029 & 8 & 18 \\
$\mathrm{~K}_{2} \mathrm{O}, \mathrm{mol} \%$ & & & & \\
16.7 & 766 & 0.030 & 11 & 20 \\
21.4 & 745 & 0.029 & 11 & 19 \\
26.9 & 733 & 0.028 & 11 & 18 \\
33 & 715 & 0.027 & 11 & 17
\end{tabular}

внутренним давлением $p_{i}=\Delta \varepsilon_{e} / \Delta v_{e}$, против которого совершается работа делокализации атома. Принимая во внимание $\sigma_{y}=p_{i}$ и соотношение для энергии делокализации атома $\Delta \varepsilon_{e}(13)$, приходим к заключению о линейной корреляции между пределом текучести $\sigma_{y}$ и температурой размягчения (температурой стеклования) $T_{g}$

$$
\sigma_{y}=\frac{R \ln \left(1 / f_{g}\right)}{\Delta v_{e}} T_{g},
$$

поскольку у стекол одного типа в данном выражении $f_{g}=$ const и $\Delta v_{e}=$ const (табл. 4). В самом деле, у ряда аморфных полимеров между $\sigma_{y}$ и $T_{g}$ обнаруживается линейная корреляция [27]. Как видно из рис. 5, микротвердость (предел текучести) силикатных стекол также линейно зависит от температуры стеклования $T_{g}$.

Таким образом, предлагаемый подход предсказывает наличие линейной корреляции между пределом текучести и температурой размягчения стекол.

Скорость термостимулированного восстановления деформированных стеклообразных полимеров как функция температуры и давления подчиняется экспоненциальной зависимости [28]

$$
i=A \exp \left(-\frac{\Delta u+p \Delta v_{y}}{k T}\right) .
$$

Для эпоксидного аморфного полимера получено следующее значение активационного объема данного релаксационного процесса: $\Delta v_{y}=(55 \pm 8) \AA^{3}$. В рамках модели делокализованных атомов скорость термостимулированного восстановления исходного состояния деформированного стекла (16) определяется скоростью изменения числа делокализованных атомов в данном процессе

$$
i \sim\left(d N_{e} / d t\right)
$$

откуда зависимость (16) выводится из уравнения модели (2). При этом активационные параметры $\Delta u$ и $\Delta v_{y}$ получают следующую трактовку: $\Delta u=\Delta \varepsilon_{e}$ и $\Delta v_{y}=\Delta v_{e}$. У сетчатых эпоксидных полимеров типа модифицированной эпоксидной смолы ЭД-16 значения объема делокализации атома $\Delta v_{e} \approx 45-74 \AA^{3}$, рассчитанные по 
формуле модели (14), имеют такой же порядок величины, что и приведенное выше значение активационного объема $\Delta v_{y}$. Для указанных эпоксидных полимеров для расчета $\Delta v_{e}$ приняты данные [29]: $T_{g}=358 \mathrm{~K}$, $\mu=0.33-0.37, E=(28-35) \cdot 10^{8} \mathrm{~Pa}$.

\section{Заключение}

Представление, что образование дырки в жидкостях и стеклах обусловлено делокализацией атома, позволяет устранить противоречия между теорией свободного объема и экспериментальными данными. Многие исследователи при рассмотрении молекулярно-кинетических процессов в аморфных веществах под свободным объемом подразумевают структурно-обусловленный вандер-ваальсов свободный объем, что иногда приводит к кажущимся противоречиям между теорией и опытом. В вязком течении стеклообразующих жидкостей важную роль играет процесс делокализации активного атома его флуктуационное смещение из равновесного положения. Результаты расчета доли флуктуационного объема $f_{g}$, замороженной при температуре стеклования $T_{g}$, по данным о вязкости и по данным зависимости $T_{g}$ от скорости охлаждения расплава приводят к одинаковым значениям $f_{g}$.

Работа выполнена при финансовой поддержке Министерства образования и науки РФ (грант № 1932).

\section{Список литературы}

[1] Сандитов Д.С. // ЖЭТФ. 2012. Т. 142. Вып. 1. С. 123-137.

[2] Сандитов Д.С., Дармаев М.В., Сандитов Б.Д. // ЖТФ. 2017. Т. 87. Вып. 1. С. 43-47.

[3] Френкель Я.И. Введение в теорию металлов. Л.-М.: Гостехиздат, 1948. 291 с.

[4] Сандитов Д.С. // ДАН. 2015. Т. 464. № 6. С. 705-707.

[5] Бетехтин В.И., Глезер А.М., Кадомцев А.Г., Киплткова А.Ю. // ФТТ. 1998. Т. 40. Вып. 1. С. 85-89.

[6] Сандитов Д.С., Бартенев Г.М. Физические свойства неупорядоченных структур. Новосибирск: Наука, 1982. $269 \mathrm{c}$.

[7] Слонимский Г.Л., Китайгородский А.И., Аскадский А.А. // Высокомолек. соед. Сер. А. 1970. Т. 12. № 3. С. 494-512.

[8] Сандитов Д.С., Бадмаев С.С. // Физ. и хим. стекла. 2015. T. 41. № 5. C. 621-630.

[9] Ferry J.D. Viscoelastic Properties of Polymers. NY., 1970. 671 р. (Ферри Дж. Вязкоупругие свойства полимеров. М.: ИЛ, 1963. 535 с.)

[10] Williams M.L., Landel R.F., Ferry J.D. // J. Amer. Chem. Soc. 1955. Vol. 77. N 14. P. 3701-3707.

[11] Бартенев Г.М. // ДАН СССР. 1951. Т. 76. № 2. С. 227-230.

[12] Сандитов Д.С. // ЖЭТФ. 2016. Т. 150. Вып. 3. № 9. С. 501515.

[13] Бартенев Г.М., Лукьянов И.А. // Журн. физ. химии. 1955. Т. 29. Вып. 8. С. 1486-1498.

[14] Бартенев Г.М., Горбаткина Ю.А. // Высокомолек. соед. 1959. T. 1. № 5. C. 769-775.
[15] Бартенев Г.М. Строение и механические свойства неорганических стекол. М.: Стройиздат, 1966. 216 с.

[16] Немилов С.В. // Физ. и хим. стекла. 2013. Т. 39. № 6. C. $857-878$.

[17] MDL @ SciGlass - 7.8 Institute of Theoretical Chemistry, Shrewsbury, MA, 2012. www.sciglass.info.

[18] Немилов С.В. // Физ. и хим. стекла. 1978. Т. 4. № 6. С. 662 674.

[19] Сандитов Д.С. Делокализация атомов и вязкое течение стеклообразующих расплавов. Германия: LAP Lambert Academic Publishing, 2016. $51 \mathrm{c}$.

[20] Мункуева С.Б. Автореф. канд. дис. Температурная зависимость вязкости стеклообразующих расплавов в широком интервале, включающем область перехода жидкость-стекло: Иркутск: Ирк. гос. ун-т, 2016.

[21] Кобеко П.П. Аморфные вещества. М.-Л.: Изд-во АН CCCP, 1952. $432 \mathrm{c}$.

[22] Ростиашвили В.Г., Иржак В.И., Розенберг Б.А. Стеклование полимеров. Л.: Химия, 1987. 192 с.

[23] Лысенко А.В., Ляхов С.А., Хоник В.А., Язвицкий М.Ю. // ФТТ. 2009. Т. 51. Вып. 2. С. 209-213.

[24] Олейник Э.Ф., Руднев С.Н., Саламатина О.Б., Котелянский М.И. // Высокомолек. соед. А. 2008. Т. 50. № 5. С. $773-788$.

[25] Чах К., Ляхов С.А., Хоник В.А. // Деформация и разрушение материалов. 2006. № 8. С. 22-25.

[26] Сандитов Д.С., Сангадиев С.Ш. // Физ. и хим. стекла. 1998. T. 24. № 6. С. 741-751.

[27] Сандитов Д.С., Сангадиев С.Ш., Сандитов Б.Д. // Деформация и разрушение материалов. 2013. № 3. С. 2-7.

[28] Магафуров И.Ш., Тополкараев В.А., Маркарян Р.Е. и др. // Высокомолек. соед. Б. 1991. Т. 32. № 2. С. 147 152.

[29] Филянов Е.М. // Высокомолек. соед. А. 1987. Т. 29. № 5. C. $975-983$. 